\title{
Transcatheter mitral valve implantation: different fixation techniques
}

\author{
Georg Lutter ${ }^{1}$, Derk Frank², Jan Hinnerk Hansen ${ }^{3}$, Yazhou Liuํ, Jochen Cremer ${ }^{1}$, Assad Haneya ${ }^{1}$, \\ Thomas Puehler ${ }^{1}$ \\ 'Department of Cardiovascular Surgery, University of Kiel, School of Medicine, Kiel 24105, Germany. \\ ${ }^{2}$ Department of Cardiology and Angiology, Christian-Albrechts-University of Kiel, Kiel 24105, Germany. \\ ${ }^{3}$ Department of Pediatric Cardiology, University of Kiel, School of Medicine, Kiel 24105, Germany.
}

Correspondence to: Dr. Georg Lutter, Department of Experimental Cardiac Surgery and Heart Valve Replacement, University of Kiel, School of Medicine, Arnold-Heller-Straße 3, Kiel 24105, Germany. E-mail: georg.lutter@uksh.de

\begin{abstract}
How to cite this article: Lutter G, Frank D, Hansen JH, Liu Y, Cremer J, Haneya A, Puehler T. Transcatheter mitral valve implantation: different fixation techniques. Mini-invasive Surg 2020;4:36. http://dx.doi.org/10.20517/2574-1225.2020.15
\end{abstract}

Received: 26 Jan 2020 First Decision: 19 Mar 2020 Revised: 14 Apr 2020 Accepted: 13 May 2020 Published: 18 Jun 2020

Science Editor: Giulio Belli Copy Editor: Jing-Wen Zhang Production Editor: Tian Zhang

\begin{abstract}
Transcatheter mitral valve implantation provides an off-pump treatment option for mitral valve regurgitation, especially for secondary mitral regurgitation. It offers an opportunity for the treatment of a large cohort of patients not referred for conventional surgery. One of the biggest challenges is the development of a valved stent that suits the complex anatomy of the native mitral valve. Furthermore, secure anchorage of the device is difficult in the mitral area without clearly defined structures. In the last few years, various new self-expanding nitinol valved stents for transapical implantation in the beating heart have been developed. Different design iterations were conducted to improve fixation and overall stent performance. The risk of paravalvular leakage was decreased and reproducibility enhanced. This article reviews the major achievements in the development process of our apically fixed mitral valved stent over the last few years, with prototypes that provide secure stent deployment, high reproducibility and low paravalvular leakage rates.
\end{abstract}

Keywords: Mitral valve, transcatheter, valved stent, off-pump, fixation techniques

\section{INTRODUCTION}

The development of transcatheter mitral valve implantation is the focus of recent research. This novel procedure provides a means to treat severe and symptomatic mitral insufficiency, especially secondary mitral regurgitation, without the need for ECMO during surgery. The transcatheter mitral valve implantation device includes heart valved stents that are implanted into the beating heart using a transcatheter-guided technique. This novel technology is ideal, especially for older patients, who are classified as high-risk patients or not 
operable. Due to the advanced age and severe comorbidities, approximately $49 \%$ of patients suffering from severe and symptomatic mitral valve insufficiency are not candidates for open-heart surgery ${ }^{[1]}$.

Challenges in the development process of such mitral valved stents include: high pressure within the left heart chamber, secure fixation to the complex anatomy of the mitral valve apparatus, absence of left ventricular outflow tract obstruction, and a tight seal to prevent the occurrence of paravalvular leakage after valved stent implantation. Due to very high pressures within the left ventricle, which act on the closed mitral valve, the development of strong systolic fixation of the device to prevent migration into the left atrium is of particular importance during the research and developmental process.

\section{TETHERED APICAL FIXATION (LUTTER VALVE)}

The first implantations of an apically tethered transcatheter mitral valve were reported in five studies between 2008 and 2013. The device was made of a self-expanding nitinol stent with a tubular ventricular part and an atrial cuff. The stent was covered with a polytetrafluoroethylene membrane and carried a trileaflet bovine pericardial valve [Figure 1]. In total, 36 pigs received off-pump mitral valved stent implantation with this device. Seventeen pigs were followed up for $1 \mathrm{~h}$ after implantation ${ }^{[2-4]}$, one animal for $6 \mathrm{~h}$, four animals for 1 week $^{[5]}$, five animals for 1 month, four animals for 2 months and one animal for 3 months ${ }^{[6,7]}$. Six animals died during the surgery or within the first hours after implantation: two suffered from ventricular fibrillation, two died from prosthesis mispositioning and two from incorrect fixation.

Transesophageal echocardiography (TEE) and computed tomography (CT) were used to evaluate stent function and correct positioning. Seven of 32 animals showed mild regurgitation after mitral valved stent implantation and a few stent fractures were observed after post-mortem valve explantation. Nevertheless, no valve stent migration, embolization, systolic anterior movement or left ventricular outflow tract obstruction was observed in the surviving animals. Gross evaluation revealed tissue coverage of the atrial element of the stent after four to eight weeks and the new, apically-tethered mitral valved stent showed good overall valve function in all cases after two and three months. These first studies demonstrated the feasibility of a reproducible method of deployment of the mitral valved stent with low gradients across the left ventricular outflow tract, and adequate stent function for up to three months in a large animal model.

\section{COMPUTED TOMOGRAPHIC EVALUATION OF DIFFERENT PROTOTYPE DESIGNS}

The in vivo shaping of mitral valved stent prototypes composed of a tubular ventricular body connected to an atrial element at different angles $\left(45^{\circ}, 90^{\circ}, 110^{\circ}\right)$ was evaluated using CT in $11 \mathrm{pigs}^{[8]}$. CT was successfully carried out 3 weeks after implantation and stent shaping, as well as left ventricular outflow tract obstruction, was controlled [Figure 2] and stent position was correct in all animals. Nevertheless, stent body deformations at the atrio-ventricular junction were detected in all cases, with the biggest deflection of the prototypes at an angle of $45^{\circ}$. A larger preset angle demonstrated less deflection and improved the alignment, thus reducing the mechanical load on the stent. Obstruction of the outflow tract was observed in two animals ${ }^{[8]}$.

\section{APICAL FIXATION FORCES}

To estimate the quantification of apical fixation forces of a tethered mitral valved stent, a study was carried out by Pokorny et al. ${ }^{[9]}$. With a specifically designed test setup, the forces acting on the apical fixation tethers were successfully measured in 18 animals [Figure 3]. The apical fixation forces were recorded following offpump mitral valved stent implantation. In this study, two different stent designs were used. The first group $(n=10)$ had a sole apical fixation and the second $(n=8)$ had additional sub-annular fixation. The mean fixation forces were higher in the former and a significant reduction of the force acting on the apex was achieved with the latter ${ }^{[0]}$. 

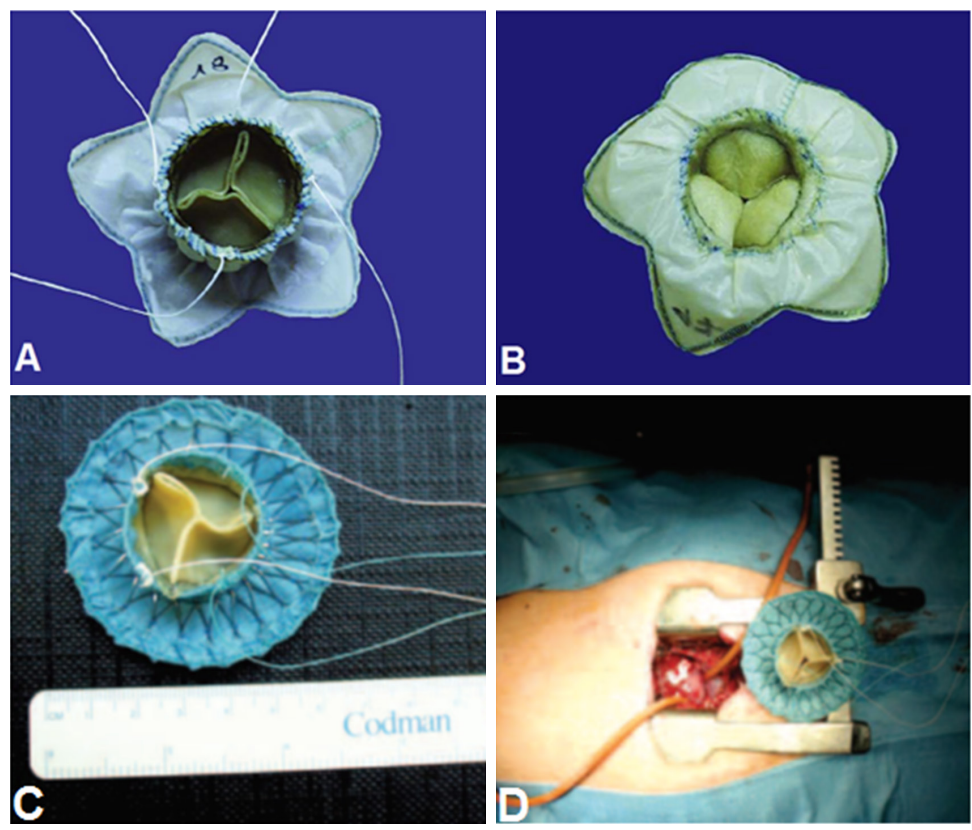

Figure 1. A: ventricular view of the atrioventricular valved stent. It consists of a bovine pericardial valve of $27 \mathrm{~mm}$ diameter, a custommade nitinol stent, and a ventricular fixation system consisting of the annular radial force of the nitinol stent and four tethers fixed at the apex; B: atrial view of the prototype valved stent ${ }^{[3]}$; C: ventricular view of the new refined mitral valved stent; $\mathrm{D}$ : operative setting after ministernotomy ( 2 inches) with this valved stent and apex of the heart with purse-string sutures is exposed ${ }^{[6]}$
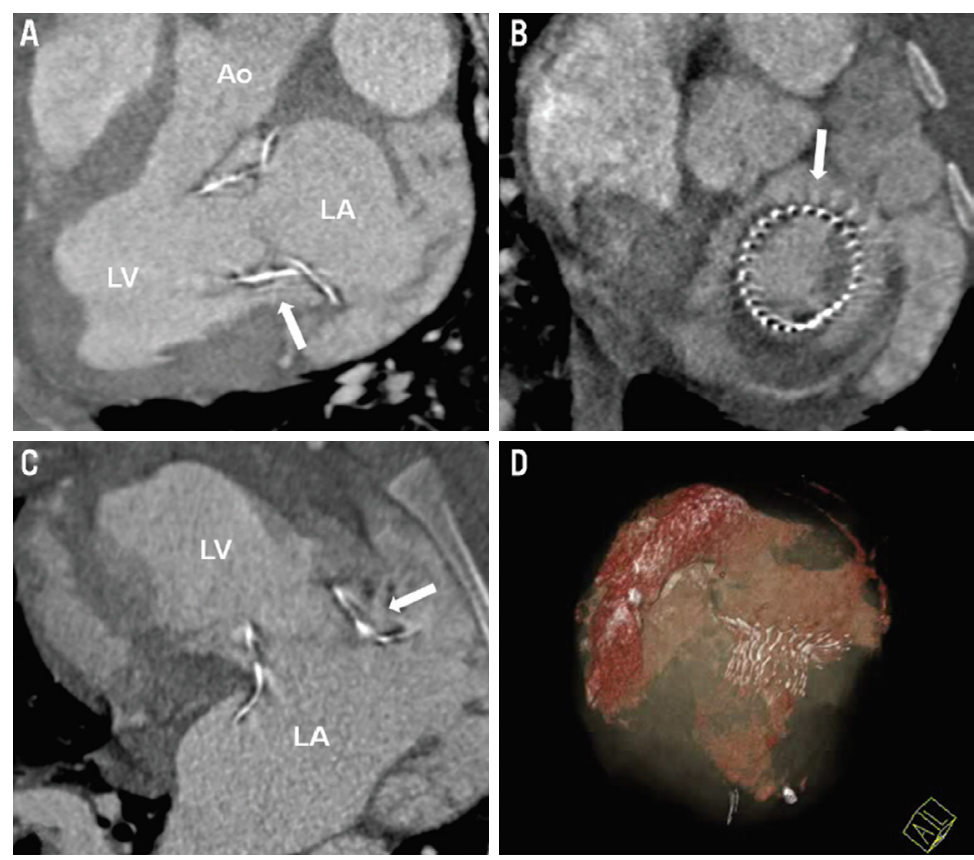

Figure 2. A-C: cardiac CT short- and long-axis standard views showing correct stent position and no left ventricular outflow tract obstruction of the $110^{\circ}$ prototype 1 month after implantation; D: three-dimensional reconstruction showing the nitinol stent frame and left atrial and ventricular volumes. Reprinted from Eurolntervention, Pokorny et al. ${ }^{[8]}$, Transapical mitral valved stent implantation: computed tomographic evaluation of different prototype designs, 948-955. Copyright (2015), with permission from Europa Digital \& Publishing. Ao: aorta; LA: left atrium; LV: left ventricle (white arrow indicates the nitinol stent frame)

\section{SUB-ANNULAR FIXATION}

A mitral valved stent with apical and additional sub-annular fixation was presented in a study in 2016 $[\text { Figure } 4]^{[10]}$. Ten pigs received off-pump mitral valved stent implantation of this novel design. Acute TEE 

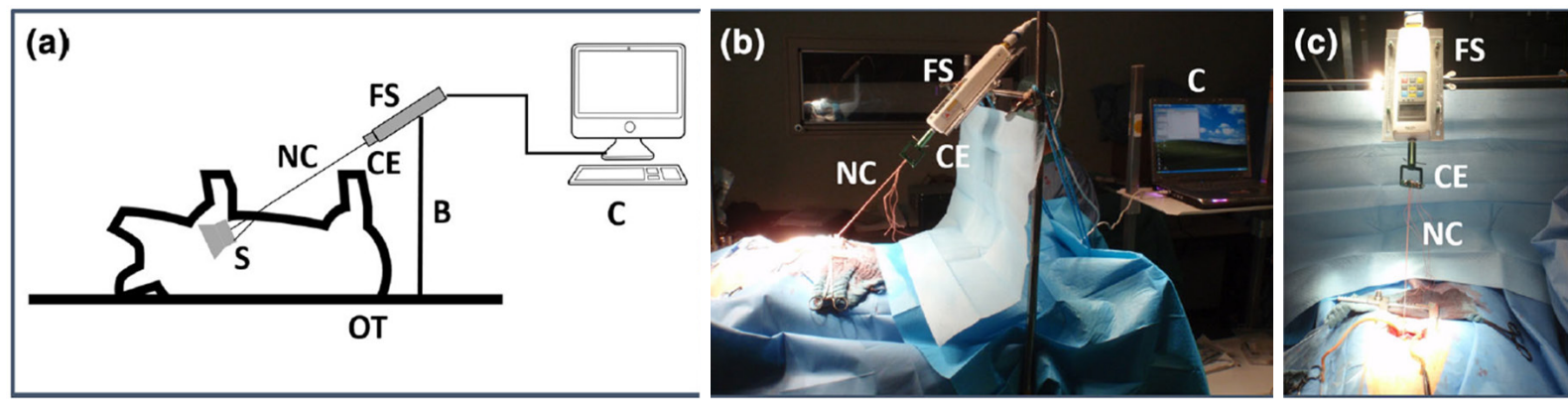

Figure 3. Illustration of the force measurement system developed: (a) schematic diagram of the test set-up; (b) lateral view of the test set-up during force quantification after mitral valved stent implantation; (c) frontal view of the FS connected to the NC via the CE. S: stent; NC: neo-chords; FS: force sensor; CE: connecting element; B: fixation bridge; C: computer for digital data recording ${ }^{[10]}$

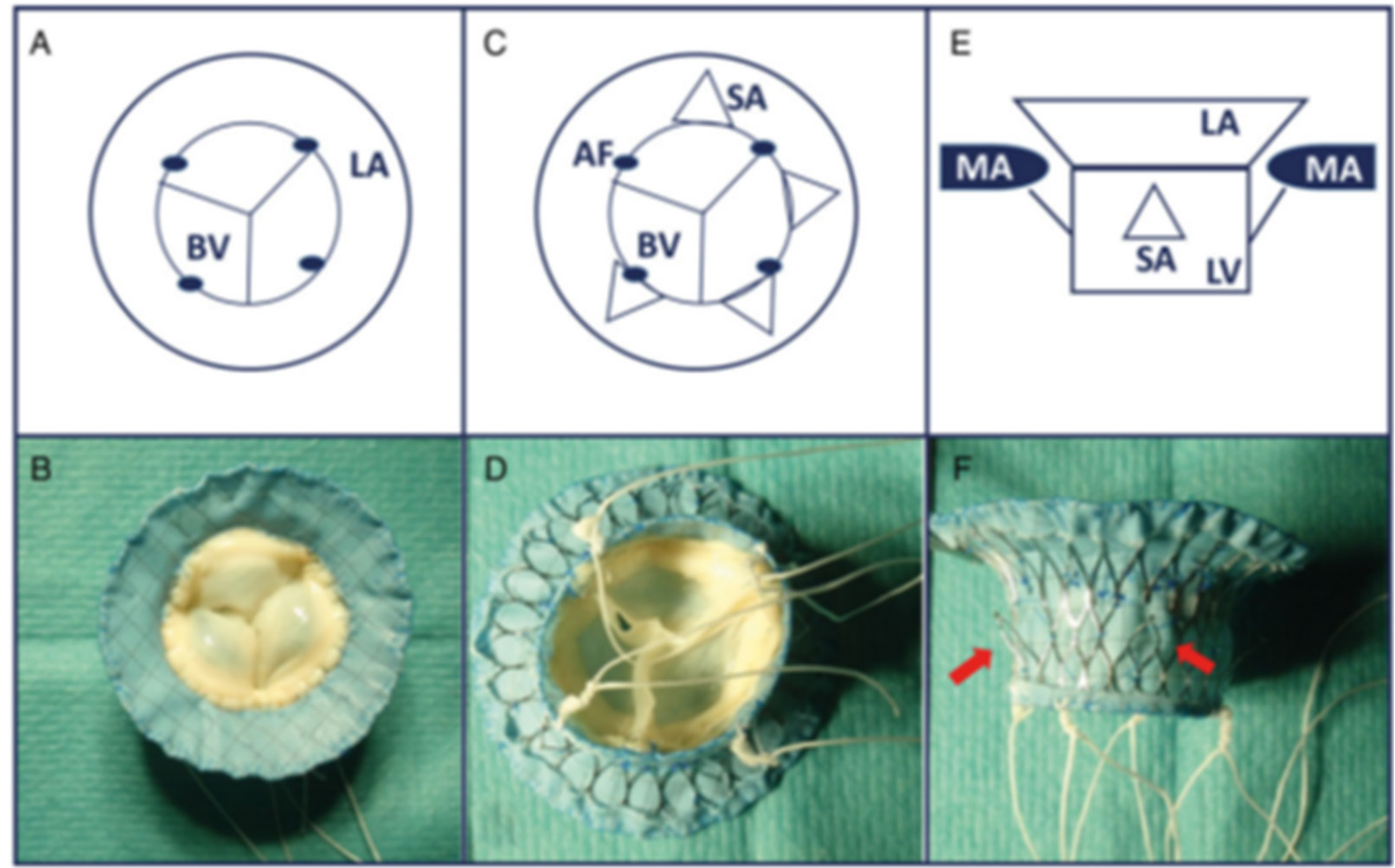

Figure 4. Illustration of the mitral valved stent prototypes with apical and additional sub-annular fixation elements (red arrows), comprising atrial element (LA), ventricular body (LV) and BV. The AF points are indicated by dots. A and B: apical view; $C$ and D: ventricular view of the prototype SA with additional subannular fixation; E and F: lateral view of the prototype SA12. LA: left atrium; LV: left ventricle; BV: bioprosthetic heart valve; AF: apical fixation; MA: mitral annulus; SA: sub-annular

and haemodynamic evaluations were assessed 60 min post implantation. Haemodynamic stability, low gradients and physiological longitudinal function were achieved. In nine cases, paravalvular leakage was trace or less. Furthermore, decreased ejection fraction, several stent fractures and an overall lower survival time compared to sole apical fixation were observed with this fixation method ${ }^{[11]}$.

\section{SUPRA-ANNULAR FIXATION}

Special small fixation hooks were developed and fabricated and a supra-annular fixation method was established. These hooks were mounted on the atrial part of the mitral stent to penetrate into the surrounding annular tissue to serve as an additional fixation [Figure $5 \mathrm{~A}$ and $\mathrm{B}]^{[10]}$. In an in vivo study 

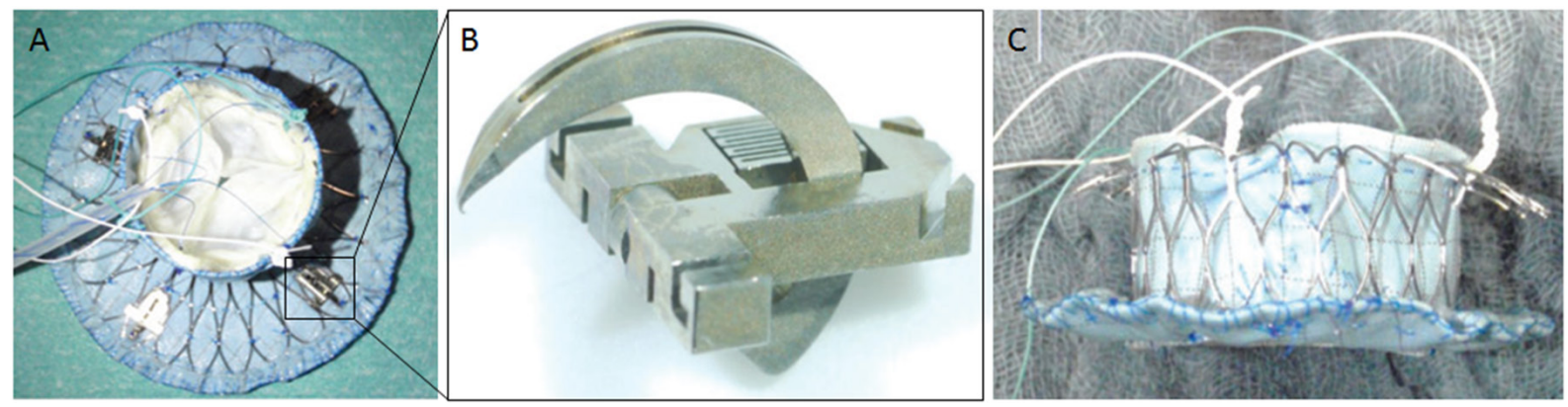

Figure 5. A: mitral valved stent with apical and additional supra-annular fixation elements; B: hook shaped elements; C: mitral valved stent with apical and subsequent sub-valvular fixation rim $^{[13]}$

with five pigs, stents were equipped with three $(n=2)$ or four hooks $(n=3)$ as well as four neo-chords for apical fixation and implanted in an off-pump procedure. A thread system enabled successful deployment of the hooks within the heart in four of five cases. One animal died within hours after implantation due to a prosthesis mismatch; one animal was sacrificed after two weeks; three animals were followed up to 1 month; and one animal was followed to three months with excellent health. Good valve function as well as normal left ventricular function was demonstrated by TEE and haemodynamic evaluation ${ }^{[1]}$.

\section{SUB-VALVULAR FIXATION}

A modified nitinol valved stent with a ventricular rim was developed for sub-valvular fixation [Figure 5C]. For secure fixation, an additional apical fixation system was attached to these stents ${ }^{[11]}$. This prototype was successfully implanted in an off-pump procedure in ten animals. A higher degree of ventricular fibrillation occurred in this group. In four of ten cases, multiple areas of infarction, arrhythmia and in one case, persistent atrial fibrillation was observed after valved stent implantation. Eight animals died within the first day of implantation. The other two animals were weaned from anaesthesia and followed up for a period of two and seven days. Nevertheless, a reduction in left ventricular ejection fraction compared to baseline values was also observed in this study group.

\section{CONCLUSION}

The correct positioning and sufficient fixation of a transcatheter mitral valved stent is a challenging task and the topic of several studies and developments in recent years. Our group specializes in the development of apical fixation methods and its in vivo evaluation. Different fixation techniques such as sole apical fixation and a combination of apical fixation with sub-annular, supra-annular or sub-valvular fixation have been presented in this review.

Even though sole apical fixation showed promising results in animal studies and already has very good results in clinical studies with the Tendyne mitral valve prosthesis in more than 150 patients (mainly in the USA and Australia), fixation force measurements demonstrated the advantage of a combined fixation strategy. In the meantime, the latter received the CE mark in March 2020. Though transseptal implantation of the mitral valved stent through the femoral access site is less invasive and expected, transapical left ventricular implantation is, at the moment, the only route to deliver the whole material to the mitral anulus and allow additional secure fixation. Perhaps smaller valve prostheses and newer fixation techniques will allow transfemoral access in the future. Consequently, different combinations of fixation concepts are continuously under development in large animal and pre-clinical studies. To succeed, in vivo quantification of mechanical deformations of the stent by CT should be performed after implantation to identify critical areas in stent design. Finally, the alignment and reduction of mechanical stress on the stent frame should be topics for further stent frame development. 


\section{DECLARATIONS}

\section{Authors' contributions}

Wrote the manuscript and invented the stent prosthesis: Lutter G

Drafted the manuscript and substantially revised it: Frank D, Hansen JH, Cremer J

Contributed tot he conception and design of the studies and performed data analysis and interpretation oft he data, they drafted the manuscript and substantially revised it: Liu Y, Haneya A, Puehler T

\section{Availability of data and materials}

Not applicable.

\section{Financial support and sponsorship}

These projects were supported by the German Research Foundation (DFG) and the German Centre for Cardiovascular Research (DZHK).

\section{Conflicts of interest}

Prof. Georg Lutter and Prof. Derk Frank: consultants to Abbott, Edwards and Medtronic. All other authors have nothing to disclose.

\section{Ethical approval and consent to participate}

Not applicable.

\section{Consent for publication}

Not applicable.

\section{Copyright}

(C) The Author(s) 2020.

\section{REFERENCES}

1. Mirabel M, Iung B, Baron G, Messika-Zeitoun D, Détaint D, et al. What are the characteristics of patients with severe, symptomatic, mitral regurgitation who are denied surgery? Eur Heart J 2007;28:1358-65.

2. Lozonschi L, Quaden R, Edwards NM, Cremer J, Lutter G. Transapical mitral valved stent implantation. Ann Thorac Surg 2008;86:745-8.

3. Lutter G, Quaden R, Osaki S, Hu J, Renner J, et al. Off-pump transapical mitral valve replacement. Eur J Cardiothorac Surg 2009;36:1248; discussion 128 .

4. Lutter G, Quaden R, Iino K, Hagemann A, Renner J, et al. Mitral valved stent implantation. Eur J Cardiothorac Surg 2010;38:350-5.

5. Lozonschi L, Bombien R, Osaki S, Hu J, Snell D, et al. Transapical mitral valved stent implantation: a survival series in swine. J Thorac Cardiovasc Surg 2010;140:422-426.e1.

6. Iino K, Boldt J, Lozonschi L, Metzner A, Schoettler J, et al. Off-pump transapical mitral valve replacement: evaluation after one month. Eur J Cardiothorac Surg 2012;41:512-7.

7. Pokorny S, Huenges K, Bähr T, Hansen JH, Fischer G, et al. Transapical mitral valved stent implantation: enhanced survival and decreased paravalvular leakages. Int J Cardiol 2014;175:418-24.

8. Pokorny S, Heinig A, Hettich H, Bähr T, Marczynski-Bühlow M, et al. Transapical mitral valved stent implantation : computed tomographic evaluation of different prototype designs. EuroIntervention. 2015;11:948-55.

9. Pokorny S, Huenges K, Engel A, Gross J, Frank D, et al. In vivo quantification of the apical fixation forces of different mitral valved stent designs in the beating heart. Ann Biomed Eng 2015;43:1201-9.

10. Pokorny S, Huenges K, Hansen JH, Schadow Y, Fischer G, et al. Off-pump mitral valved stent implantation: comparison of apical and subannular fixation techniques. Eur J Cardiothorac Surg 2017;51:112-8.

11. Loger K, Lutter G, Huenges K, Frank D, Groß J, et al. Transcatheter mitral valve implantation: supra-annular and subvalvular fixation techniques. Eur J Cardiothorac Surg 2018;54:1013-21. 